\section{Qualitative Data Collection, Analysis and Presentation: A Theoretical Overview}

\author{
Laya Prasad Uprety, Ph.D
}

\begin{abstract}
This paper explains the significance of the interpretive approach in the regime of qualitative research which underscores the search of the meanings in human cultures and subjectivities in the human behavior. Its overall emphasis has been on the processes, stages, and goals of conventional ethnographic research, qualitative data analysis and their presentation in the academic and professional reports. However, the theoretical analysis has been heavily influenced by "positivism" and hence, it has failed to address many of the issues emerged in the regime of contemporary qualitative research approach.
\end{abstract}

Key Words: Qualitative, ethnographic, positivism, interpretive, subjectivity, analysis and presentation.

\section{Prelude}

The fundamental objective of this overview paper is to help the beginners of social science research understand the theoretical underpinnings of qualitative research, its data collection procedures generally used in the field settings, modes of qualitative data analysis and style of the presentation of qualitative data in the texts of reports/ scientific papers. The paper has been divided into nine short sections. The first section introduces the objective and structure of the paper. The second section helps to conceptualize social research in general. The third section presents the conceptualization of positivist approach in survey/quantitative research and interpretative approach in qualitative research in social research. Sections four and five, respectively, deal with the qualitative data collection in the field through the use of ethnographic method and participatory rural appraisal (PRA) techniques. Section six basically helps to understand the mechanics of taking and managing field notes while conducting the qualitative studies. Similarly, sections seven and eight, respectively, present the modes of qualitative data analysis and conventional style of qualitative data presentation in the texts of reports/ scientific papers. Finally, the last section presents the conclusions.

\section{Understanding Social Research}

\section{Notion of Research:}

The English word 'Research' is derived from French word 'Rechercher' which means to 'seek again'. Research is the systematic search for pertinent information on a specific topic (Cordoasco and Gatner, 1958:1). Scientific research is systematic, controlled, empirical, and critical investigation of hypothetical propositions about the presumed relations among natural phenomena (Kerlinger, 1973:11). Social research may be defined as, "scientific undertaking, which by means of logical and systematized techniques, aims to: (i) 
discover new facts or verify and test old facts; (ii) analyze their sequences, interrelationships, and causal explanations which were derived within an appropriate theoretical frame of reference, and (iii) develop new scientific tools, concepts, and theories which would facilitate reliable and valid study of human behavior” (Young, 1988: 30). A scientific study, in the last analysis, is a means to an end; that is, it aims to solve a problem- practical or theoretical or methodological. It aims at discovery, verification and validation, and finding relationships among the accumulated data. These feats can be accomplished by means of scientific method, that is, logical and systematized application of the fundamentals of science to the general and overall questions of a study, and scientific techniques which provide precise tools, specific procedures, and technical, rather than philosophical, means for getting and ordering the data prior to the logical and statistical manipulation (ibid:32).

\section{Typology of Social Science Research:}

\section{Pure or Basic or Theoretical Research:}

Research is conducted for generating knowledge for the sake of knowledge. Knowledge acquired may be used for constructing theoretical models. In other words, knowledge may be organized into propositions and these propositions may then be meaningfully articulated. Such use of knowledge is often labeled as theory-oriented, and activities of a scientist who seeks knowledge for the sake of building theories are often known as pure or basic or theoretical research. The knowledge has the non-utilitarian import (Wilkinson and Bhandarkar (1992:20). More precisely, knowledge for the sake of knowledge, that is, only for the satisfaction of 'knowing' is the attitude that underlies scientific of this order (ibid).

\section{Practical or Applied Research:}

Knowledge may be used as a means to some practical or utilitarian goal and not construed just as an end in itself... The researches which seek knowledge mainly for the sake of serving some practical ends are often called 'applied', 'action-oriented' or 'practice -oriented'...(ibid).

\section{Action Research:}

Action research is a process that combines learning and action to produce more effective change. When focused on empowerment, it helps people set their agenda and improve their work and lives. It assists people in investigating and studying their actions, reflecting on them and developing ways to increase their effectiveness and impact. As a result, it promotes deeper understanding and learning, and greater commitment to the changes being pursued (Chapman et.al, 2005). Participatory research can be defined by different levels and types of local involvement of local stakeholders in and control over the research process. It includes such methodologies as Participatory Rural Appraisal (PRA), Participatory Action Research (PAR), and Farmer Participatory Research (FPR). The rationale for using the participatory research is to encourage community participation in order to improve the usefulness of research to local people. Another reason may be empowerment or social transformation to strengthen the local people's capacity in decision-making in research, and in management of local resources, in order to improve their awareness of options and to strengthen their ability to act on their own behalf (McAllister,1999:7 and Ashby,1996:17, quoted in Uprety, 2003). Participatory action research is an alternative 
philosophy of social research often associated with social transformation in the Third World. The key characteristics of participatory action research as analyzed by Kemmis and McTaggart (2005: 563) include: planning a change; acting and observing the process and consequences of change; reflecting on these processes and consequences; re-planning; acting and observing again and reflecting again, and so on. Such research is thought to involve a spiral of the aforementioned reflective cycles.

At its best, participatory action research is a social process of collaborative learning realized by groups of people who join together in changing the practices through which they interact in a shared social world in which, for better or worse, we live with the consequences of one another's actions (Kemmis and McTaggart, 2005: 563). Additionally, the key features for action research as the self-reflective spiral are: (a) participatory action research is a social process (explores the relationship between the realms of the individual and the social- e.g teachers working together with students to improve of processes of teaching and learning in the classrooms); (b) participatory action research engages people in examining their knowledge (understandings, and skills and values) and interpretative categories (the ways in which they interpret themselves and their action in the social and material world); (c) participatory action research is practical and collaborative; (d) participatory action research is emancipatory (helps people to be free from constraints of irrational/unjust social structures); (e) participatory action research is critical/reflexive, and participatory action research aims to transform both theory and practice. The overall focus of the research has been on empowerment (Kemmis and
McTaggart,2005: 566-68). Such participatory action researches are mostly qualitative in nature.

Understanding Facts/Data in Social Science Research:

"Facts" and "data" are probably the most frequently referredto terms in scientific writings, yet these terms are among the most difficult to define. "Facts are defined as "what has really happened." But facts are not limited to the tangibles. Thoughts and feelings and sentiments are facts in social science. Data are defined as "facts, figures known or available; information". P.V. shares that this assertion may not very helpful for the researcher (Young, 1988:10). Facts must be seen as physical, mental, or emotional occurrences or phenomena which can be affirmed with certainty and are accepted as true in a given "world of discourse". Data are more than "facts, figures", more than "information", "events," or "experiences", more than memories of a teller of life histories. Data are the all the relevant materials, past and present, serving as bases for study and analysis. They are "the living stuff, with all the relevant emotional (and mental) signs attached", to one's expressions, actions, attitudes, and values within his social world" (ibid). An investigator has to be intent on obtaining reliable, verifiable and measurable data (ibid:11).

\section{Understanding Research Design within Social Sciences:}

According to P.V. Young (1988), the social researcher, either guided by desire to gain knowledge or by an urgency to solve a problem scientifically, works out a plan of study. At the beginning, this plan is generally vague and tentative. It undergoes many modifications and changes, as the study progresses and insights into it deepen. The working out of the plan consists in reality of making certain decisions with respect to: (i) what the study is about and types of data that 
are needed; (ii) why the study is being made; (iii) where the needed data can be found; (iv) where or in what areas, the study will be carried on; (v) when or what period of time, the study will include; (vi) how much material or how many cases will be needed; (vii) what bases of selection will be used, and (viii) what techniques of gathering data will be adopted (ibid:12). This design framework is also equally important for the conventional qualitative research.

\section{Science: Theory and Fact}

Science:

Science is popularly defined as an accumulation of systematic knowledge... Science is a method of approach to the entire empirical world, that is, to the world which is susceptible of experience by man. The sole purpose of science is to understand the world in which man lives (Goode and Hatt, 1952:7). Scientific method is based on these criteria: (i) reliance on empirical evidence; (ii) use of relevant concepts-symbols/logical constructions created from sense impressions/experiences; (iii) commitment to objectivitysetting aside the subjective considerations by the practitioner of science; (iv) ethical neutrality-no personal prejudice in research; (v) generality-generalizations; (vi) predications based on probability, and (viii) public methodology affording testing of conclusions through replications- criticism is the very life-blood of science- Karl Pearson (Wilkinson and Bhandarkar,1992:4-14).

\section{Theory and Research:}

According to Goode and Hatt (1952), theory and fact are not opposed but are inextricably intertwined. A fact under research is regarded as an empirically verifiable observation... Theory refers to the relationships between facts, or to the ordering of them in some meaningful way... The development of science can be considered as a constant interplay between theory and fact/research. A theory is a toll of science in the following way: (i) it defines the major orientation of a science, by defining the kinds of data, which are to be abstracted ( it narrows the range of facts to be studied/ defines which kinds of facts are relevant); (ii) it offers a conceptual scheme by which the relevant phenomena are systematized, classified and interrelated (theory as conceptualization and classification-e.g uses of the terms/concepts of class systems, social mobility, socialization, and social distance in sociology/ anthropology).; (iii) it summarizes facts into empirical generalizations, and systems of relationships between propositions; (iv) it predicts facts, and (v) it points to gaps in our knowledge. Researches/facts, on the other hand, contribute to: (i) initiate a theory (e.g the accidental finding that the penicillium fungus inhibits bacterial growth); (ii) reject and reformulate the existing theory ( rejection of earlier theories of suicide by E. Durkheim which were based on psychopathology, climate, race, nationality, and he developed different classification of suicide and a theory of social and personal disorganization), and (iii) redefine and clarify theory (testing existing theory is likely to redefine it) (Goode and Hatt,1952:8).

\section{Conceptualizing Positivist Approach in Survey/Quantitative Research and Interpretative Approach in Qualitative Research}

Positivist Approach in Survey/Quantitative Research: As indicated in the preceding section, Bernard (1988:12) asserts that science is an objective, logical and systematic 
method of analysis of phenomena, devised to permit the accumulation of reliable knowledge. Hence, three words, namely, objective, method and reliable (the norms of science), are especially important in the regime of research as elaborated by Bernard.

I. Objective: Striving for objectivity is useful. In practice, this means constantly trying to improve measurement (to make it more precise and more accurate) and submitting to our findings to peer review, or what Robert Merton called the “organized skepticism”.

II. Method: Each scientific discipline has developed a set of techniques for gathering and handling data, but there is, in general, a single scientific method. The method is based on three assumptions: the reality is out there to be discovered; that direct observation is the way to discover it, and that material explanations for observable phenomena are always sufficient, and that metaphysical explanations are never needed.

III. Reliable: Data have to be true.

As explicated by Jary and Jary (1991), positivism is the doctrine formulated by August Comte- father of sociologywhich asserts that the only true knowledge is scientific knowledge, i.e. knowledge which describes and explains the co-existence and succession of observable phenomena. Comte's positivism has two dimensions: (i) methodological and (ii) social and political, in that positive knowledge of social phenomena was expected to permit a new scientifically grounded intervention in politics and social affairs which would transform social life. Bernard asserts that in choosing the term positivism, Comte conveyed his intention to repudiate all reliance on earlier speculative bases of knowledge. However, he regarded scientific knowledge as 'relative knowledge', not absolute. Absolute knowledge was, and always would be unavailable.

Generally speaking, positivism, as analyzed by Jary and Jary (1991), also means any sociological approach which operates on the general assumption that the methods of physical science (e. g. measurement, search for general laws, etc) can be carried over into the social science. Hence, social scientists can conduct the scientific social surveys with enough rigor to understand the social realities.

\section{Interpretative Approach in Qualitative Research:}

Interpretative approach basically underscores the search of meaning in human cultures. Apropos of it, Clifford Geertz (1973) asserts, "The concept of culture I espouse... is essentially a semiotic one. Believing, with Max Weber, that man is an animal suspended in webs he himself has spun, I take culture to be those webs, and the analysis of it to be therefore not an experimental science in search of law but an interpretative one in search of meaning. It is explication I am after, construing social expressions on their surface enigmatical...”(Geertz, 1973: 5). Borrowing a notion of Gilbert Ryle, Geertz defines ethnography as a "thick description". In short, anthropological writings are themselves interpretations. Ethnographic descriptions are microscopic. Interpretative practice engages both hows and the whats of social reality; it is centered in both how people methodologically construct their experiences and their worlds, and in the configurations of meanings and 
institutional life that inform and shape their realityconstituting activity (Holstein and Gubrium, 2005: 485).

Phenomenological school of Edmund Husserl focuses on the experiential underpinnings of knowledge- a function of active relation between perception and its objects. Human consciousness actively constitutes objects of experience. His project is to investigate the structures of consciousness that make it possible to apprehend an empirical world. Schutz argues that the social sciences should focus on the ways that the life world-the world every individual takes for granted-is experienced by its members. From this perspective, the scientific observer deals with how the social world is made meaningful. There has been the focus on the subjectivity and inter-subjectivity (ibid).

Ethno-methodology considers how members themselves of society orient to and use cultural rules, norms and shared meanings to account for the regularity of their actions. All actions are indexical; they depend upon context. Events have equivocal or indeterminate meanings without a discernible context. It is through contextualization that practical meaning is derived. Ethnographic studies tend to focus on locally crafted meanings (ibid).

Explanation is a tricky business, one that qualitative inquiry embraces discreetly in the light of its appreciation for interpretative elasticity. It is one thing to describe what is going on and how things or events take shape, but the question of why things happen the way they do can lead to inferential leaps and empirical speculations that propel qualitative analysis far from its stock-in-trade. The challenge is to respond to why questions in ways that are empirically and conceptually consonant with qualitative inquiry's traditional concerns" (ibid: 499).

It is contextual to make a distinction between the quantitative and qualitative research. Debus and Novelli (1986:5) have made an effort to make a simplistic distinction. They have argued that generally quantitative research: (a) measures level of occurrence; (b) asks "how" many", and "how often"; (c) studies actions; (d) is objective; (e) provides proof; (f) is definitive; (g) measures level of actions, trends, and so on, and (h) describes. Conversely, qualitative research: (a) provides the depth of understanding; (b) asks "why"?; (c) studies motivations; (d) is subjective (e) enables discovery; (f) is exploratory; (g) allows insights into behavior, trends, and so on, and (h) interprets.

They have further argued that by its very nature, qualitative research deals with the emotional and contextual aspects of human responses rather than with objective, measurable behavior and attitudes. In reality, qualitative research is complementary to quantitative research. Flexibility is the main characteristic of such research. However, no attempt is made to draw firm conclusions or to generalize results to the population at large because it involves small numbers of the respondents who are not generally sampled on a probability basis (ibid: 2)

Likewise, three keys have been identified by Debus and Novelli for the successful research. These comprise: the art of asking "why?”; (ii) the art of listening, and (iii) research as a creative process of investigation. In asking "why"?, the experienced qualitative researcher has to be careful to: (a) ask in a neutral manner; (b) avoid leading the respondent; (c) ask only one question at a time; and (d) note verbal and non- 
verbal clues of confusion or evasion from the respondent. A good researcher has to use indirect questions. Creative listening requires a high degree of sensitivity, intuition and reflection, as well as accuracy. Things to keep in mind about listening include: (a) active listening is closely related to empathy, one's ability to identify with another in terms of the way that person would feel or act; (b) the things are said may reveal more of the intended meanings than the words that are spoken; and (c) good listening requires hearing what is meant as well as what is said. This means picking up on non-verbal clues- indicators of anxiety and uncertainty, of confidence and assertiveness. Hesitations, silences and variations in word choice are also relevant. With respect to the creative process of investigation, the key to getting the right answers is to adapt and create the process to suit the specific research issue. A high level of creative thinking must be applied to each new situation if the qualitative research process is to be truly successful (ibid: 4).

\section{Qualitative Data Collection through Ethnographic Method}

Prior to gaining the understanding on qualitative data collection and its procedures/techniques, it is essential to understand what is ethnography or ethnographic method. Seymour-Smith (1986:98-99) shares that the term 'ethnography' is used with two distinct senses: that of ethnographic research (i.e fieldwork) and that of an ethnographic monograph (ethnographic writing). As a category of anthropological research, ethnography is characterized by the first-hand study of a small community or ethnic group. Such studies combine varying degree of descriptive and analytical elements, but the central characteristic of conventional ethnographies is that they focus on one specific culture or society and consider theoretical or comparative generalization from the standpoint of the ethnographic example.

There has been a trend in the anthropology that these ethnographic studies are predominantly qualitative and holistic in nature. Use of ethnographic method has been a long tradition in the regime of structural-functional anthropology. Fieldwork under ethnographic studies involves living in close contact with a research population in order to observe their daily routines, ritual and social acts, economic activities, and other aspects of cultural behavior. It has assumed the methodological prominence with the rise of interest in an ahistorical, "structural-functionalist" study of human social and cultural systems (Pelto and Pelto, 1997).

According to Pelto and Pelto (1997), this orientation of the ethnographic interest began in the decade of 1915-1925, particularly following the appearance in 1922 of major theoretical works by A.R.Radcliffe- Brown (The Andaman Islanders) and Bronislaw Malinowski (The Argonauts of the Western Pacific). Malinowski is often credited with being the originator, or least the major developer, of the style of fieldwork that involves intensive and long-term immersion in the daily lives of native people (long residence, use of native language, and deep involvement with the people). Pelto and Pelto share that when Malinowski was developing the functionalist ideas, the sociologists in Chicago were also developing the community studies. Their research tended towards holistic, qualitative descriptions of life in face-toface communities. This approach was later adopted by some noted anthropologists such as Robert Redfield who embarked on a holistic study of the Mexican village of Tepoztlan in 1920s. The community study, whether sociological or 
anthropological, is in part a natural development from the idea of intensive, long-term field-work. The field worker who takes up residence within a research population finds himself becoming a member of particular community (town, village, band, or other local social unit). He develops close friendship and working ties with its members. Often he is assigned ties of fictive kinship within the social network. The emphasis is on community as a research unit to understand whole culture. Not all ethnographic works are community studies, of course. Pelto and Pelto also assert that new ethnography represents a return to intensive interviewing of a few key informants. In these studies, using techniques of "componential analysis" or other specialized "emic" analysis of taxonomic categories, the unit of research is usually the "culture" as expressed in a particular language. Finally, Pelto and Pelto argue that there has also been a humanistic-scientific dilemma in the ethnographic research. It involves the seeming contradictions between the necessity for humanistic, emphatic "understanding" of the way of life of a people, which is generated in part through the fieldwork process itself, and equally important matter of developing scientifically objective, verifiable modes of observation. However, the more usual attitude in recent anthropological writing seeks an amalgam, a judicious mixture of the two aspects of the research enterprise. In other words, there is need to use both rigor and insights. So there is need to describe exactly how ethnography is done, how insights are derived, and how judgments about the data are made. In recent days, the dilemma is resolved by means of an eclectic, qualitativequantitative mix of fieldwork methods (Pelto and Pelto, 1997:243-246).

G. Berreman (1968) notes that the ethnographers and villagers are both performers and audiences to each other.
Each side seeks to present a certain image of self, but the audience (especially the ethnographer) will attempt to glimpse the back region (of the theatrical scene) in order to gain new insights into the nature of the performance and performers. The ethnographer or researcher is treated as a marginal native in the field. A fieldworker does not assume a role of full native in all respects. Nor do the natives think of the anthropologist or researcher as a completely assimilated member of the local social order. The fieldworker is always a marginal person, an outsider who, if he/she is successful, is permitted relatively free access to the backstage area of the local scene (Pelto and Pelto, 1997).

\section{Entering the Field for the Ethnographic or Qualitative Research:}

Bernard (1988) shared that a good field worker has to consider a number of factors before entering the field. These comprise: choosing the field site that promises to provide easiest access to data; going into the field with plenty of written documentation about him/her and his/her work (letters of introduction from the university, funding agency or client); using personal contacts (to the extent possible) to help make the entry into the field site; thinking through in advance what he/she will say when people ask about him/her and his/her work; spending time getting to know the physical and social layout of field site.

\section{Researcher/ Fieldworker/Ethnographer at Work:}

Pelto and Pelto (1997) have shared that the most successful researchers/ethnographers have the personal flexibility, humility, and sensitivity. The successful fieldworkers have been those who are able to meet field research community on the basis of face-to-face interaction. According to them, some norms to be followed include: (i) acceptance of local food 
and drink (first step to fieldwork is to build rapport so that it is essential to overcome some squeamishness with regard to both flavor and sanitation); (ii) use of the local language (fieldwork necessitates learning language of the people being studied because the structures and cultures of language constitute an important body of information about the stuff of cultural behavior; there is also symbolic, social-solidarity aspects of language use; (iii) participation in the local social scene (participant observation is the vital fieldwork technique); (iv) avoidance of authoritarian and judgmental behavior (mixing with people without considering one's own superiority, eschewing negative value judgments concerning the morality, goodness, or aesthetic worth of behavior encountered in the research community, etc; are very important and the overall focus has to be on cultural relativism); (v) flexibility (the above points must not be interpreted as a list of do's and don'ts of proper fieldwork style. The essential point is that no such list of do's and don'ts is possible, as a general schema around which the fieldworker builds up his social relationships (Pelto and Pelto,1997: 251-256).

Pelto and Pelto (1997) further argue that the successful fieldworker does not seek to apply particular rules of procedures, but rather trains himself to be sensitive receiver of social feedback, by means of which he constantly adjusts his behavior to suit his style and modes of conduct of the local community. They have considered friendship as a strategy of fieldwork (The essence of successful ethnography is a form of behavior that makes the fieldworker a friend of the community he studies and a special friend of a number of persons within it). The fieldworker must also consider the observer-effects (making careful note of the situations in which the researcher's presence appears to influence patterns and outcomes of events is also important) and the myth of total acceptance (Everyone may not like the researcher/ethnographer and he/she also may not like all of them. He/she may have some enemies).

\section{The Stages of Ethnographic Fieldwork/Field Research:}

There has been a tradition in anthropology that a good qualitative research can be done over a period of about a year. However, this amount of protracted time is not necessary in all short-term qualitative researches. But if the researcher is supposed to spend considerable amount of time for the qualitative research, he/she has to take care of the different stages of qualitative research. The understanding of these stages also helps the short-term qualitative researchers to plan their activities accordingly. In this context, Bernard (1988:162-169) shares his understanding on the different stages for the intensive anthropological fieldwork or qualitative research (to be done with the use of participant observation). These subsume: (i) initial contact (The field researcher may have euphoria and excitement in new culture while making contacts with the people but there is also the chance of encountering the unpleasant things); (ii) shock (The ethnographer experiences culture shock because he/she finds himself/herself a stranger in a strange land. He/she confronts a cultural scene much different from anything one is accustomed to. There may be suffering from uncomfortable stress response which subsides as the researcher settles in or in other words, there may be the psychological disturbances at the initial stage, loneliness, inability to communicate effectively with the local people, difficulties in finding houses and other practical concerns, plus confusion of figuring out where to start and for the temporary depression, 
psychotherapy training prior to the fieldwork has been found to be useful. Similarly, adequate research trainings/ orientations have also been found to be useful in reducing the training); (iii) discovering the obvious (discovering necessary good stuff, i.e relevant data, both tangible and intangible); (iv) the break ( it helps for putting things into perspective, focusing on how much has been achieved and planning for the remaining); (v) focusing (helps to have a better idea of exactly what kind of data the researcher is lacking); (vi) exhaustion, the second break, and frantic activity (opportunity for taking stock, ordering priorities for time remaining, and evaluating the achievements as well as using the little precious time most productively, and (viii) leaving the field (ritual leaving of the place in a culturally appropriate way by informing the people).

Goal of Ethnographic Fieldwork in the Regime of Qualitative Research: Bronislaw Malinowski's View (1922)

The goal of ethnographic fieldwork in the regime of qualitative research must be approached through three avenues as articulated by Malinowski (1922) as follows: (i) the organization of the tribe or community, and the anatomy of its culture must be recorded in firm, clear outline; (ii) within this framework, the imponderabilia of actual life and the type of behavior have to be filled in, and (iii) a collection of ethnographic statements, characteristic narratives, typical utterances, items of folk-lore and magical formulae has to be given as documents of native mentality. Thus, according to Malinowski, the goal of ethnographic research is to grasp the native's point of view, his relation to life, to realize his vision of his world (Malinowski, 1922:24-25).

\section{Research Techniques under Ethnographic Method}

Discussing the approaches to the ethnographic research, Ellen (1993) argues that ethnographic fieldwork not only provides the empirical data base, but also of the strongly held feeling (although not always fully articulated) that the act of having done the fieldwork is a sine qua non for admission to full professional standing and to the recognition by one's own peers of the validity of a claim to be anthropologist.

Ethnographic method in research generally involves the following key research techniques/approaches: (i) key informant interview; (ii) field (participant) observation; (iii) case approach; (iv) informal discussion, and (v) genealogy.

(i) Key informant interview is an important tool within the ethnographic method. Bernard writes that, "key informant interviewing is an integral part of the ethnographic research. Good informants are people... who understand the information you need, and who are glad to give it you or get it for you..." (Bernard, 1994: 166).

There has also been a practice of choosing good key informants for the ethnographic or qualitative research because it relies on a few key informants rather than on a representative sample. Therefore, an important question for such research is: are a few informants really capable of providing adequate information about a culture? This can be answered affirmatively but it does hinge on two things: (i) choosing good informants, and (ii) asking them things they know about (Bernard, 1988). This shows that competence of the key informants is to be considered by the qualitative researchers. 
(ii) Participant observation is the foundation of anthropological research. Discussing about the importance of the participant observation under the ethnographic method, Bernard (1988: 148) writes, “...It (participant observation) involves establishing the rapport with a new community; learning to act so that people go about their business as usual when you show up; and removing yourself everyday from cultural immersion so you can intellectualize what you have learned, put it into perspective and write about it convincingly...”.

It is necessary to observe, listen to and converse with informants in as free and natural an atmosphere as possible. The assumption is that the most important behavior of people in groups is a dynamic process of complex interactions and consists of more than a set of facts, statistics or even discrete incidents. The strength of this kind of method is in the observation of natural behavior of people in real life settings. Another assumption is that human behavior is influenced by the setting in which it occurs. It is necessary to make efforts to understand the setting and the nature of social structure; its traditions, values and norms of behavior. It has been important for the researchers to observe and interpret the collected facts using etic approach but emic perspective has to be taken into consideration (Bernard, 1988 and Best and Kahn, 1992).

There have been the opinions that participant observation, as a form of social interaction, always involves impression management. Impression management in the ethnographic research is often an exhausting, nerve-wracking effort on both sides, especially in the early phases of the contact (Berrman, 1972). Until the contact with the subjects is not established fully, the ethnographer obtains only the official view or publicly approved view on the variables under the study. And after that, he starts having access to "back-region information" or "secrets" of the community.

Bernard (1988:1949-52) insists that there are five reasons for insisting on participant observation in the conduct of scientific research about cultural groups. These are: (i) participant observation is a strategy that facilitates the collection of data in the field- all kinds of data, both qualitative and quantitative; (ii) it reduces the problem of reactivity- that is, people changing their behavior when they know that they are being studied ( as the researcher becomes less and less of a curiosity, people take less and less interest in your comings and goings; they go about their business and let you do bizarre things of collecting data).Lower reactivity means higher validity of data; (iii) it helps you formulate sensible questions in the native language; (v) it gives you an intuitive understanding of what is going on in a culture, and allows you to speak with confidence about the meaning of data, and (vi) many research problems simply cannot be addressed adequately by anything except participant observation (e.g how a local meeting of user group committee works or how a court functions in its proceedings?).

Bernard (1988:52-60) also cautions that a participant observer has to have a number of skills for good field work. These comprise: (i) using the native language; (ii) building explicit awareness of the little details in life; (iii) building memory (i.e building the ability to remember things you see and hear is crucial to a successful participant observation research); (iii) maintaining naivete (i.e developing skills at being a novice- at being someone who genuinely wants to learn a new culture), and (iv) building writing skills ( i.e developing the ability to write comfortably and clearly).

Direct observation is also instrumental in garnering in the necessary information and data on the physical location of the study area, social infrastructures, topography, hydrological 
systems, natural resources, settlement patterns, agricultural practices, people's behavioral practices, etc. This tool is enormously useful to cross-check/triangulate the informants' answers.

(iii) Case approach: Case study is often used in anthropological/qualitative research. P.V.Young (1988) asserts that a fairly exhaustive study of person or group is called life or case history. A comprehensive study of a social unit-be that unit a person, a group, a social institution, a district, or a community- is called a case study. Thus, case study is approach which views any social unit as whole. It deepens our perceptions and gives us a clearer insight into life. It gets at behavior directly and not by an indirect and abstract approach. Case data may be gathered exhaustively of an entire life cycle of a social unit (life history) or a definite section of it (case study). Whether a section or the whole of a life is studied, the aim is to ascertain the natural history, that is, an account of the generic development of a person or group, revealing the factors that molded the life of the unit within its cultural setting. Because of its aid in studying behavior in specific, precise detail, Burgess termed the case study, "social microscope". Use of both positive and negative/marginal cases is necessary. Statistics never tells the whole stories. Anthropologists and ethnologists have utilized the case study method for their detailed descriptions of primitive and modern cultures. "Personal life-records" constitute the perfect type of sociological materials because they represent a more enlightening and fundamentally more real record of personal experiences. There are also the practices of using the personal documents--diaries, letters, and autobiographies -- as the chief instruments for reaching the actual attitudes and values of people as well as for obtaining a cross-section of the entire process of social becoming (Young, 1988).

Goode and Hatt (1952:331) asserts that case study is a way of organizing social data so as to preserve the unitary character of the social object being studied. Expressed somewhat differently, it is an approach which views any social unit as a whole. Almost always, it includes the development of that social unit, which may be a person, a family or any other social group, a set of relationships or processes (social adjustment/invasion etc) or even an entire culture.

Young (1988) also shares that case data furnish the bases for the generalizations provided the data are accurately and impartially recorded. She has listed a number of criteria for conducting the case studies: (i) The subject must be viewed in a cultural series (the subject must be regarded as a member of culture group/community and community values, standards and ways of life can be studied); (ii) Behavior of the individuals must be viewed as socially relevant (behavior should be seen as arising in response to definite social stimulations); (iii) The family of the subject must be viewed in its role of submitting the culture and way of life of the group through its individual members; (v) The continuous related character of experience from childhood through adulthood should be stressed; (vi)The specific method of elaboration of organic materials into social behavior must be shown (need to examine the cultural milieu to determine what factors actually account for the particular life pattern under scrutiny); (vii) The "social situation" must be studied in order to learn kind and degree of social pressures, social forces, social participation or abstention, exercised by the subject, 
and (viii) The life history/case study material must be organized and conceptualized (Young, 1988).

Young (1988) has further shared that case studies of persons should have their starting point not in the life history of that person but in the social situation and group he/she is part. The case data, rich in intimate detail, supplies not only a portrait of human personality and social situations but also a basis upon which hypotheses relevant to the study can be built. She also lists some of the values of case studies. These comprise: (i) the case method is not in itself a scientific method at all, but merely a first step in scientific procedure; (ii) individual cases become of scientific significance only when classified and summarized in such forms as to reveal uniformities, types and patterns of behavior; (iii) the statistical method is the best, if not the only, scientific method of classifying and summarizing large number of cases. The two methods are not, therefore, under any circumstances opposed to each other, nor is the one a substitute for the other. In fact, cases are the perfect types of sociological materials. Case data are capable of revealing the interests, motives, and inner lives of persons and the meaning the social world assumes in their outlook on, and reactions to, life. Case data tend to represent the natural development of a life-cycle of a person or of an evolving process of social situation with all complex interrelated factors (ibid).

Despite these values, Young (1988) also points out the limitations of case studies. These could be: (i) the greater the rapport, the more subjective the whole process is; (ii) the subject is more likely to be self-justificatory than factual, and (iii) case situations are seldom comparable in a pluralistic universe of discourse (ibid). (iv) Informal discussions: Informal discussion with the local people also helps to understand their views about various aspects related to community in their areas. Such discussions are to be held while walking in the sample area, eating food and drinking tea at the local hotels/tea stalls, waiting for a bus/jeep, making the direct observation of the people's behavior, etc.

(vi) Genealogy: Seymour-Smith (1986) shares that while conducting the qualitative studies on the social structure of any community, anthropologists have a trend to use genealogy to collect data on the relationships of descent by maintaining a record or account. Genealogies have been considered important in lineage or descent-based kinship systems because they provide the basis for membership in kin groups. In other words, genealogies are the reflections of the characteristics of present day social and kinship structure.

While drawing a diagram of kinship ties, symbols are used. A triangle is used for male and a circle is used for female as shown below.

\section{$\Delta$ : male}

$\circ$ : female

Genealogical data are basically used for the study of kinship and marriage, inheritance of property, inheritance of political power, and identification of descendents and siblings.

(v) Content Analysis: In addition to the above, there is a research technique called "Content Analysis" generally used by the researchers in journalistic/communication research. In this context, Dooley (2003) shares that content analysis is method that count occurrences of selected words or phrases or sentences in a sample of text or speech. This approach helps to quantify the emphasis given to certain kind of 
content by counting the number of words or lines of print referring to the topic. The resulting data helps explore the way media handles different kinds of issues. But this can be used by other qualitative researchers. Young (1988) shares that content analysis/categorization is a process of making note that is divided into sentence or phrase units, which represent fragment of behavior (an attitude, an emotion, or an overt act) to which labels of categories may be assigned. For example, in the content analysis of the life history of Anna Pavlove (a Molakan family), 151 concepts were listed (and used) such as cultural conflict, occupational mobility, parents struggle against the assimilation of youths, youth's assimilation problems, resistance to native heritages, cultural hybridism, and other such concepts. It helps to make the inferences from the texts of the letters, diaries, ethnographic notes, newspapers, articles, editorials, minutes of meetings, autobiographies, essays, and stories (Young, 1988).

\section{Qualitative Data Collection through Participatory Rural Appraisal}

According to Theis and Grady (1991), Participatory Rural Appraisal (PRA) is a specific form of Rapid Rural Appraisal (RRA), a research technique developed in late 1970s and early 1980s by researchers in development as an alternative and complement to conventional sample surveys. PRA is a way of learning from, and with, community members to investigate, analyze, and evaluate constraints and opportunities, and make informed and timely decisions regarding development projects. It is method by which a research team can quickly and systematically collect information for: general analysis of a specific topic, question, or problem; needs assessments, feasibility studies, identifying and prioritizing projects, and project or program evaluations. The approach of PRA owes more to anthropology and ethnographic research methods than to sociology and sample surveys. In other words, its purpose is to gain an understanding of the complexities of a topic rather than to gather highly accurate statistics on a list of variables. Moreover, in PRA understanding qualitative nuances (subtle differences) within a topic is just as important as finding general averages. It is applied most effectively in relatively homogenous rural communities which share common knowledge, values, and beliefs. In brief, PRA is an intensive, systematic but semi-structured learning carried out in a community by a multi-disciplinary team which includes community members. It requires attitudes favoring participation, respect for community members, interest in what they know, say, show, and do, patience, not rushing, and not interrupting, listening, not lecturing, humility, methods which empower community members to express, share, enhance, and analyze their knowledge. PRA has a number of features which include: triangulation, multidisciplinary team, mix of techniques, flexibility and informality, community-based, collection of necessary and accurate data only, on-the-spot analysis, and off-setting biases (by asking the cross-sections of population) and being self-critical. The main advantages of PRA over conventional survey research are its level of community participation, short duration, and low cost. Using the ethnographic research method (prolonged stay, use of participant observation, key informant interview, etc), the PRA researcher becomes an insider for a limited period. This method is particularly suited for gaining an understanding of a community's selfperception (an insider's perspective) (Theis and Grady, 1991:22-33).

PRA offers a wide range of techniques which facilitate involvement of the community in all aspects of project 


\section{2 | Laya Prasad Uprety}

design, implementation, monitoring, and evaluation. This ensures that the community members are empowered and take a stronger interest and larger role in their development activities (ibid:38). In addition to the specific techniques used from the ethnographic methods delineated above, a wide range of other specific techniques are also used in PRA. These include: review of secondary data, focus group discussion, group discussion, preference ranking, matrix ranking, wealth ranking, participatory mapping (social, resource and mobility), transect walk, seasonal calendar, timeline, trend diagrams, flow or causal diagram, venn or institutional diagram ethno-history, oral history, stories, folk taxonomy, etc. The objective of his paper is not to deal all techniques specified above. However, a few techniques related to semi-structured interviewing have been dealt with. These comprise individual interview, group interview and focus group discussion. The reason of dealing with them is that they are most frequently used by the PRA practitioners and other researchers in the field for generating the qualitative data.

\section{Individual Interview:}

Individual interviews help to obtain representative information. Information obtained from the individual interviews is more personal than from group interviews, and is more likely to reveal conflicts within the community since respondents may feel they can speak more freely without their neighbors present. Interviews are conducted with an opportunity sample of purposely selected individual respondents (e.g farmer leaders, innovative farmers, women farmers, poor farmers, traditional farmers, etc. to be selected if the researcher is studying local modern farming system). When a wide range of respondents are interviewed on the same topic, it is possible to reveal a wide range of opinions, attitudes and strategies. Emphasis has to be laid on informants' personal knowledge/behavior/perceptions, and not about others. Many communities have at least one "trouble maker" who disagrees with everything. Responses from these persons can provide valuable cross-checks and reveal useful insights that may not result from other interviews. Random interviews with passers-by (e.g; during cross walks) may also reveal useful information and unexpected viewpoints (ibid:52).

\section{Group Interview:}

Group interviews help to obtain community-level general information. They provide access to a larger body of knowledge, and provide an immediate cross-check on information as it is received from different people in the group. At the most, there can be up to 20 participants in the group. Group interviews are not useful for discussion of sensitive information. Efforts are to be made to express alternative opinions during the group interviews (ibid: 53).

\section{Focus Group Discussion:}

Focus group discussions (FGDs) are primarily used to discuss specific topics in detail. A small group of people (six to 12) who are knowledgeable or who are interested in the topics are invited to participate in the focus group discussions. A facilitator is chosen to ensure that the discussion does not diverge too far from the original topic and that no participant dominates the discussion. A note taker is also required in the discussion so that the facilitator uses his/her time exclusively in moderating the discussion (ibid: 53). 


\section{Emphasis on Triangulation:}

All these above tools/techniques discussed under the ethnographic method and PRA help for triangulating the data/information needed for the qualitative study. "Triangulation" is the core aspect of the qualitative research.

\section{Mechanics of Taking and Managing Field Notes While Conducting the Qualitative Studies: Bernard (1988)}

According to Bernard (1988:181-82), five basic rules to remember for taking and managing fieldwork notes are as follows:

(i) Do not try to put all your notes into one, long, running commentary. Use plenty of paper; make many shorter notes than fewer longer ones.

(ii) Separate your note taking into four physically separate sets of writing. These are: field jottings, field notes, a field diary and a field $\log$.

(iii) Take field jottings all the time, not just at appointed times during the day. Keep a note pad with you at all times and make field jottings on the spot, whenever you see something or hear something that strikes you as important. Field jottings are the basis of field notes.

(iv) Be sensitive to the feelings of the informants, and it is sometimes a good idea to just listen attentively to an informant and leave your notebook in your pocket.

(v) Set aside a time of day that you devote to writing up field notes from your jottings.
Bernard (1988) also shares his view on the discrepancies between and among field notes, diary, and log. Field notes are based on observations that form the basis of the report. A diary is personal that helps the fieldworker to deal with loneliness, fear, and other emotions that make fieldwork difficult. It also helps him/her interpret his/her field notes, and makes him/her aware of his/her personal biases. A log is a running account of how the fieldworker plans to spend his/her time, how he/she actually spends his/her time, and how much money he/she spends. He also distinguishes three types of field notes to be maintained by the field researchers. These are as follows:

\section{(i) Methodological Notes}

Methodological notes deal with the techniques in collecting data. They have to do with the conduct of field inquiry itself. You will have to make notes especially when you do something silly that breaks a cultural norm.

\section{(ii) Descriptive Notes}

The bulk of the field notes are descriptive. Descriptive notes are the meat and potatoes of the fieldwork in qualitative research.

\section{(iii) Analytic Notes}

They are the product of the fieldworkers' understanding, and that comes about through organizing and working with descriptive and methodological notes over a period of time.

\section{Conceptualizing Qualitative Data Analysis}

Analysis means the categorizing, ordering, manipulating, and summarizing of data to obtain answers to research 
questions. The purpose of analysis is to reduce data to intelligible and interpretable form so that the relations of research problems can be studied and tested (Kerlinger, 1978:134). Analysis is a continuous process of reviewing the information as it is collected, classifying it, formulating additional questions, verifying information, and drawing conclusions. Analysis is the process of making sense of the collected information (Theis and Grady, 1991). Interpretation takes the results of analysis, makes inferences pertinent to the research relations studied, and draws conclusions about these relations. The researcher who interprets research results searches for their meaning and implications (Kerlinger,1978: 134 ). Bernard (1988:319-21) shares that qualitative analysis -in fact, all analysis - is the search for patterns in data and ideas that help explain the existence of those patterns. It starts even before you go to the field and continues throughout the research efforts. The researcher has to employ the emic perspective and document folk analyses. However, it is also equally important to retain the etic perspective.

\section{Thematic Classification of Data: A Process of Qualitative Data Analysis}

Organizing the data from the field descriptive notes under the different themes/sub-themes by reading them carefully is the thematic classification of data (it can be done in the computer directly or a broad sheet paper as per the convenience). In this context, Goode and Hatt (1952) have deliberated upon on the qualitative coding for the thematic analysis in qualitative research. They have shared that qualitative coding comprises all the techniques for classifying reliably the social data on which very little or no order has been previously imposed by the researcher. When data are classified by using existing theoretical models or pre-determined categories, the problems of analysis are mainly mechanical. But when the social data have to be classified as per the concepts or categories or themes or subthemes emerged in the process of investigation, the problems are very complex. Therefore, we must learn how to classify the qualitative data. And it is necessary to develop the explicit set of instructions for ordering the data to derive the meaningful generalizations. The main steps in qualitative coding as described by Goode and Hatt (1952) are as follows: (i) clarify what is that is desired from the materials (as per the purpose to answer the research questions); (ii) study the completed schedules/notes of interviews or participant observations very carefully; (iii) work out the classes/possible groupings (using concepts/categories/themes) and the indicators of the classes/groupings; (iv) fit the classes/groupings to the data, and code all the answers.

While organizing the data, always take note of the commonalities and differences in the data. Once organizing the data begins, one does not have to record the same common information if it appears again and again in the text of the field descriptive note. However, he/she has to record the different information on the same issue if it appears every time. Generalizations/conclusions are to be substantiated by the specific set of information.

\section{Conventional Style of Qualitative Data Presentation: Bernard (1988)}

Bernard (1988:322) asserts that qualitative data analysis depends heavily on the presentation of selected anecdotes 
and comments from informants- quotes that lead to reader to understand quickly what it took you months or years to figure out. But one has to try not to use the jargony writing by avoiding the plain English. The researcher should not fill up his/her writing with lengthy quotes from informants with no analysis at all. Definitely, data do not speak for themselves. The researcher has to develop his/her ideas (analysis) about what is going on, state those ideas clearly, and illustrate them with selected quotes from the informants.

Bernard (1988:324-29) also shares that an important part of qualitative analysis is the production of visual displays. Laying out data in table or matrix form, and drawing theories out in the form of a flow chart or map, helps to understand what the researcher has and is a potent way to communicate ideas to others. Learning to build and use qualitative data matrices and flow charts requires practice, but one can get started by studying examples published in research reports/journals.

Bernard (1988:229-31) further shares that causal maps represent theories about how things work. They are visual representations of ideas that emerge from studying data, seeing patterns, and coming to conclusions about whatcauses-what. After all, it is better to know how much one thing causes another than to know simply that one thing does cause another.

Bernard (1988:335-342) asserts that one of the most commonly used techniques in qualitative analysis is the production of native taxonomies, or folk taxonomies. A native taxonomy is a description of how people divide up domains of culture, and how the pieces of domain are connected. By “domain” we mean simply a list of words in a language that somehow belong together. Some domains are very large and inclusive, others are small and narrow; some lists are known to all speakers of a language, others represent highly specialized knowledge.

Finally, Bernard (1988:342-45) has shared that componential analysis is a step toward an "operationally-explicit methodology for discovering how people construe their world of experience from the way they talk about”. Borrowing from linguistics, it is used in cultural anthropology for studying domains of culture. Initially, it was used for studying kinship terms. In fact, what can be done is impressive, intuitively compelling analysis of meanings that people attach to terms in their languages.

Shrestha (1985) shares that cartographic tools can also be used to interpret the relationships and analyze trends. Analysis by classification (i.e systematic grouping of objects or events into classes on the basis of properties or relationships they have in common and the grouping can be accomplished by two routes: by logically subdividing a population, or by agglomerating like individuals) is the usual practice in the qualitative data analysis.

\section{Conclusions}

In the contemporary world, there has been a growing emphasis on the combination of the qualitative and quantitative tools and techniques in the social research because the judicious mixture in methodology can always give a better integrated and comprehensive picture of what we investigate in the society and culture. Collection of 
qualitative data requires deeper understanding on the application aspect of every technique and skill for deeper probing the issues on intangible variables and prepare elaborate descriptive and analytical notes in the fields which would be used as the meat and potatoes (Bernard!) for the interpretive writing. Qualitative data analysis also requires serious effort from the part of the researcher for the systematic and thematic classification of unorganized/raw data into the understandable fashion without missing/ignoring the nitty-gritty of the research realm so that meaningful generalizations with broader implications can be derived. Qualitative data have to be presented in a lively way with an interpretive perspective and in so doing, meaningful generalizations on the relationships between and among the variables under study have to be presented first followed by native people's voices as the accompanying substantiations. Last but not the least, all the interpretations furnished above are heavily influenced by positivistic episteomological stance.

\section{References:}

Bernard, H.R. (1988). Research Methods in Cultural Anthropology. New Delhi: Sage Publication, India.

Bernard, H.R.(1994).Research Methods in Anthropology: Qualitative and Quantitative Approaches. New Delhi: Sage Publications.

Berreman, G.D. (1972). Hindus of the Himalayas: Ethnography and Change. Berkeley: University of California.

Chapman ,J. Pereira, A, Okwaare, S, Uprety, L. P, Azumah, V and Miller, V. (2005). Critical Webs of Power and Change: Resource
Pack for Planning, Reflection and Learning for People-centered Advocacy. London: Action Aid International.

Debus, Mary and Novelli, Porter.(1986). Methodological Review: A Handbook for Excellence in Focus Group Research. Washington D.C: Academy for Educational Development.

Denzin, N.K. and Lincoln,Y. (2005). “The Introduction: Discipline and Practice of Qualitative Research" in Denzin, N.K. and Lincoln, Y (eds.) Qualitative Research .London: Sage Publication.

Dooley, David (2003): Social Research Methods. New Delhi: Prentice Hall of India Pvt. Ltd.

Geertz, Clifford. (1973). The Interpretation of Cultures. New York: Basic Books Inc; Publishers.

Goode, W.J and Hatt, P.K. (1952). Methods in Social Research. Sydney: Mcgraw-Hill, Kogakusha,Ltd.

Holstein, J.A. and Gubrium, J.F. (2005). "Interpretive Practice and Social Action” in Denzin, N.K. and Lincoln,Y (eds.) Qualitative Research . London: Sage Publication.

Jary, David and Jary, Julia. (1991). Collins Dictionary of Sociology. Glasgow: Harper Collins Publishers.

Kemmis, S and Mctaggart, R. (2005). "Participatory Action Research: Communicative Action and Public Action” in Denzin, N.K. and Lincoln,Y (eds.) Qualitative Research. London: Sage Publication.

Kerlinger, F.N. (1978). Foundations of Behavioral Research. Delhi: Surjeet Publications, India. 


\section{2 | Laya Prasad Uprety}

Experiences from the Study of Two Indigenous Irrigation Systems from Western Terai" in Uprety, et. al. (eds.), Nepalese Journal of Qualitative Research Methods vol. 1 pp.1-20. Lalitpur: Local Initiative Promotion Trust (LIPT).

Pelto,P.J and Pelto, G.H..1997. "Ethnography: The Fieldwork Enterprise” in J.J. Honigmann (ed.) Handbook of Social and Cultural Anthropology.Vo.1. New Delhi: Rawat Publications, India.pp.241-288.

Shrestha, C.B. (1985).” Non-statistical Tools of Analysis” in G.R. Agrawal and A.K. Lal Das (eds.) Fundamentals of Social Science Research Methodlogy. Kirtipur: CEDA, Tribhuvan University.

Seymour-Smith, C. (1986). Macmillian Dictionary of Anthropology. London: Macmillian Press LTD.

Theis, J. and Grady, H.M. (1991). Participatory Rapid Appraisal for Community Development: A Training-based Manual on Experiences in the Middle East and North Africa. International Institute for Environment and Development and Save the Children Federation.

Uprety, Laya Prasad. (2003). "Participatory Action Research in Community Forestry: A Case Study of Community Forest Users' Group from a Village of Eastern Nepal” in Regmi, et.al (eds.) Occasional Papers in Sociology and Anthropology.Vol.VIII. Kirtipur: Central Department of Sociology/Anthropology, Tribhuvan University, Nepal.

Uprety, Laya Prasad (2006). Managing Water for Irrigation as a Common Property Resource: A Case Study of Sorah-Chhattis Mauja Indigenous Irrigation Systems of Rupandehi District. Unpublished Ph.D Dissertation. Kathmandu: Tribhuvan Unversity, Nepal.

Uprety, Laya Prasad (2007). “Use of Qualitative Research Methods in Natural Resources Management Studies: Some Anthropological
Valbuena,V.T. (1985). "Qualitative Content Analysis" in MA.Lourdes S.Bautista and Stella P.Go (eds.) Introduction to Qualitative Research Methods. Manila: Research Center, Delasalle University, The Phillippines.

Wilkinson, T.S and Bhandarkar, P.L. (1992). Methodology and Techniques of Social Research. Delhi: Himalaya Publishing House.

Wolf, H.K and Pant, P.R. (1975). A Handbook for Social Science Research and Thesis Writing. Kirtipur: Tribhuvan University.

Young, P.V. (1988). Scientific Social Survey and Research. New Delhi: Prentice Hall of India Pvt. Ltd. 